\title{
Efficiency and Sustainability of Microfinance Institutions: A Comprehensive Review of Literature
}

\author{
Preeti Gupta*
}

\begin{abstract}
Microfinance is the provision of thrift, credit and other financial services and products of very small amounts to the poor. Although the word finance is in the term microfinance, and the core elements of microfinance are those of the finance discipline, microfinance has yet to break into the mainstream or entrepreneurial finance literature. It has become one of the most discussed subjects in the last two decades all over the world. Today micro finance programs and institutions have become gradually more important components of strategies to reduce poverty or promote micro and small enterprise development. This, in turn, gives rise to the importance of the issue of efficiency as well as sustainability of Microfinance Institutions (MFIs) especially in developing countries like India. The purpose of this paper is to provide a comprehensive review of literature addressing the issues of MFI's sustainability and efficiency levels.
\end{abstract}

Keywords: Microfinance, Efficiency, Sustainability.

\subsection{Introduction}

Microfinance can be called a novel approach to provide saving and investment facility to the poor around world. Improved access and efficient provision of savings, credit, and insurance facilities in particular can enable the poor to smoothen their consumption, manage their risks better, gradually build their asset base, develop their business, enhance their income earning capacity, and enjoy an improved quality of life. Microfinance is the provision of thrift, credit and other financial services and products of very small amounts to the poor for enabling them to raise their income levels and improve their living standards. It has been recognised that micro finance helps the poor people meet their needs for small credit and other financial services. The informal and flexible services offered to low-income borrowers for meeting their modest consumption and livelihood needs have not only made micro finance movement grow at a rapid pace across the world, but in turn has also impacted the lives of millions of poor positively.

Research Scholar, Department of Commerce, Delhi School of Economics, University of Delhi 
The two main mechanisms for the delivery of financial services to such clients are: (1) relationship-based banking for individual entrepreneurs and small businesses; and (2) group-based models, where several entrepreneurs come together to apply for loans and other services as a group. Microfinance, according to Otero (1999) is "the provision of financial services to low income poor and very poor self-employed people". These financial services according to Ledgerwood (1999) generally include savings and credit but can also include other financial services such as insurance and payment services. Schreiner and Colombet (2001) define microfinance as "the attempt to improve access to small deposits and small loans for poor households neglected by banks." Therefore, microfinance involves the provision of financial services such as savings, loans and insurance to poor people living in both urban and rural areas who are unable to obtain such services from the formal financial sector. Microfinance clients are typically employed, often house hold based entrepreneurs. In rural areas, they are usually small farmers and others who are engaged in small income generating activities such as food processing and petty trade. In urban areas, microfinance activities are more diverse and include shopkeepers, service providers, artisans, street vendors, etc. Microfinance clients are poor and vulnerable non-poor who have a relatively stable source of income. Microfinance is the term that has come to refer generally to such informal and formal arrangements offering financial services to the poor.

Efficiency indicates how well organisations utilise their resources to produce goods and services, and the rate at which the input resources are used to produce or deliver the outputs. The concept of efficiency is defined as better use of resources in order to maximize the production of the goods and services of the firms (Kipesha, 2013). It is concerned with the relationship between the input resources such as labour costs, capital and equipment and the output produced using the inputs (Farrell, 1957). Measurement of efficiency in MFIs is very essential because it provides information about the firm performance. It facilitates MFIs in establishing better management policies to reduce wastage of resources and identification of factors which helps in improving efficiency. Although efficiency studies on formal financial institutions such as banks are numerous, the literature in microfinance is somehow very limited. There are remaining gaps for the efficiency study in microfinance which need to be filled, considering the importance of microfinance institutions and their roles to the economy. While efficiency studies can be done using either parametric or non-parametric analysis, most of microfinance studies preferred non-parametric Data Envelopment Analysis (DEA) to parametric Stochastic Frontier Analysis (SFA) due to some limitations of SFA and advantages of DEA. An example is SFA does not incorporate arguments that are not expressed in monetary units into the function, which is possible for DEA (Kablan, 2012). 
Measures of efficiency studies are divided into parametric and non-parametric methods. Based on banks efficiency studies, common parametric methods are the Stochastic Frontier Approach (SFA), the Thick Frontier Approach (TFA) and the Distribution Free Approach (DFA), while the common non-parametric techniques are the Free Disposal Hull analysis (FDH) and the Data Envelopment Analysis (DEA) (Mokhtar et. al. 2006). There are very limited studies in the efficiency of MFIs, especially in the poor and developing countries

Microfinance is one of the ways of building the capacities of the poor and graduating them to sustainable self-employment activities by providing them financial services like credit, savings and insurance. To provide microfinance and other support services, MFIs should be able to sustain themselves for a long period. An ongoing debate exists about how feasible it is for microfinance institutions to reach the very poor while maintaining financial viability. Several studies of microfinance organisations (MFOs) have found no relationship between outreach and sustainability. Throughout the world, financial sustainability of microfinance institutions has been one of the issues that have recently captured attention of many researchers due to its importance in the livelihood of microfinance institutions. The financial sustainability of microfinance institutions is a necessary condition for institutional sustainability (Hollis and Sweetman, 1998), and the most important requirement for any MFI. The need for MFIs to be financially sustainable cannot be overemphasised. It has been argued that unsustainable MFIs might help the poor now, but they will not help the poor in the future because the MFIs will be gone. This shows how important the sustainability of MFIs is, and studying factors that affect sustainability of MFIs so that sustainability can be improved. In the academic literature, however, we find surprisingly few rigorous testing of this issue.

The present paper is an attempt to provide an insight into efficiency and sustainability level and factors affecting efficiency and sustainability of MFIs.

More specifically, the objectives of the study are:

(a) To provide thorough understanding of the concept of microfinance, efficiency and sustainability.

(b) To conduct an in-depth review of various studies in the area of microfinance, specifically focusing on efficiency, sustainability and performance analysis of microfinance institutions.

Some discussion is also made upon performance analysis of MFI as efficiency, sustainability and performance of any MFI is interrelated and interconnected. In order to present a coherent review of the broad microfinance literature, literature review section is divided into three areas of microfinance i.e. efficiency, sustainability and performance analysis of MFIs. Accordingly, the remainder of the paper proceeds as follows. Section 
2 sheds light upon review of literature; this section is further divided into three sections, i.e. efficiency, sustainability and performance analysis of MFIs. The summary and conclusion of the paper is provided in section 3 .

\section{Review of Literature}

This section is divided into 3 subsections. Section 2.1 reviews studies focusing on efficiency of MFIs: this section is further categorised into subsection, the first part provides review of studies on efficiency of MFIs using Data Envelopment Analysis (DEA) technique and second part includes studies on efficiency of MFIs using other techniques except DEA. Section 3.2 addresses institutional sustainability, or the notion that MFIs need to be financially selfsufficient (free of subsidies) for optimal results, while Section 3.3 throws some light on studies focusing on performance analysis of MFIs.

\subsection{Studies focusing on Efficiency of MFIs}

(i) Studies focusing on efficiency of MFIs using DEA approach

Data envelopment analysis (DEA) is used to analyse the efficiency of the microfinance institutions in India. DEA is a linear programming methodology to measure the efficiency of multiple decision-making units (DMUs) when the production process presents a structure of multiple inputs and outputs. DEA has been used for both production and cost data. DEA is performed under two approaches, the intermediation approach and the production approach. Majority of studies applied DEA techniques to ascertain the efficiency of MFIs as it can be applied on small sample, review of such major studies is presented in this section.

Nietoa et al. (2007) and Haq et al.(2009) have attempted to determine efficiency of MFIs in Latin American Countries on a sample of 30 and 39 MFIs respectively with the help of DEA technique. The results of the former study suggested that high level of cost efficiency had decreased due to the amount of non-performing loans specifically for bank-MFIs under the intermediation approach. However, Haq et al. extended the study in Asian and African countries also. Findings of this study revealed that non-governmental microfinance institutions particularly; under production approach, were the most efficient and this result was consistent with their fulfilment of dual objectives i.e. alleviating poverty and simultaneously achieving financial sustainability. Similar kind of study conducted by Hassan and Sanchez (2009) focused on investigating technical and scales efficiencies of MFIs in three regions: Latin America countries, Middle East and North Africa (MENA) countries, and South Asia countries, and compared 
efficiencies across regions and across type of MFIs on sample of 30 MFIs. Technical efficiency(TE) was found to be low for MFIs, regardless of the approach used, which implied that MFIs were wasting resources (input oriented inefficient) and were not able to produce enough outputs whereas scale efficiencies were found relatively high.

There are also few set of studies which tried to compare efficiency level of MFIs in different countries. Ferdousi (2013) and Tahir and Tahrim (2013) tried to investigate the comparative performance of microfinance institutions (MFIs) in 3 and 5 Asian countries respectively. Former study took two countries from South Asia: One was the micro finance pioneering country Bangladesh, and another was India which was the largest emerging market for micro finance industry, among East Asian countries china was selected. Findings of the study revealed that MFIs in China and India performed more efficiently than that of Bangladesh under constant return to scale technology but under variable return to scale technology MFIs in Bangladesh performed more efficiently than others. Moreover, it was also found that the performance of MFIs in terms of total assets and financial performance in terms of profitability is critical for sustainable and efficient development of MFIs. On the other hand sample countries selected by Tahir \& Tahrim were Indonesia, the Philippines, Vietnam, Cambodia and Laos for the period of 2008 to 2011. They found that MFIs in Vietnam were relatively more efficient than their counterparts with efficiency levels of $87.6 \%$ in 2008 and 2009, 90.8\% in 2010 and $91.3 \%$ in 2011. The results implied that improvements are necessary especially in reducing excessive usage of inputs. Whereas one more study was conducted in South Asian region but the main aim of the study was to identify the most efficient/best practice MFI(s) that would in turn help improve functioning of the other MFIs in the South Asian region, which comprises of $20 \%$ of the World poor(Qayyum and Ahmad,2011). It was found that eight MFIs from Pakistan, six MFIs from Bangladesh and five MFIs from India were at the efficient frontier under variable returns to scale further it was revealed that the inefficiencies of MFIs in Pakistan, India and Bangladesh were mainly of technical nature. The results further suggested that most of the MFIs experiencing increasing returns to scale were in Bangladesh.

However, there are few country specific studies, like Ahmad (2011) estimated efficiency of MFIs in Pakistan in order to analyse that how many institutions were efficient in delivering credit to the poor section in the year 2003 and 2009 respectively. He concluded that a microfinance institution is said to be financially sustainable if without the use of subsidies, grants, or other concessional resources, it can profitably provide finance to micro enterprises on an acceptable scale. Rani (2013) ascertained the financial efficiency of selected five diamond profile Indian MFIs for the period 20052010. She suggested that MFIs can become more efficient only by having a strong 
internal auditing, internal control and monitoring systems. These institutions should be more ethical not only in disclosure of financial performance but also social performance.

\section{(ii) Studies focusing on efficiency of MFIs using other approaches}

There are few studies which did not apply DEA in order to measure efficiency level and relied upon other techniques such as DEA, self-organising maps, certain ratios etc. After DEA, Stochastic Frontier technique is also being widely used to estimate the efficiency of MFIs. Nieto (2009) attempted to combine financial and social information in the form of an efficiency index that combines the financial and social aims of an MFI. The achievement of the social aims of the MFI was measured through its impact on women and through a poverty index. It was also that there are no MFIs that were socially efficient but financially inefficient, something that is consistent with the view that in order to meet their social responsibilities, MFIs have to be financially sound. It was found that there is a significant and positive relationship between efficiency in supporting women and efficiency in fighting poverty. NGOs were found more socially efficient than the MFIs that were running under other organisational structures. This confirms the findings of earlier studies.

Masood and Ahmad (2010) and Eric et al. (2010) tried to measure the efficiency level and its determinants of a sample of MFIs operating in India with the help of stochastic frontier approach (SFA). Results of these studies were almost similar and exhibited that experience (age) of the MFI was an important determinant of efficiency level but size did not matter much and no trade off was found between efficiency and outreach in case of sample of MFIs included in the study. Similarly by applying stochastic frontier technique the technical efficiency of different types of MFIs in Latin America were also examined by Roselia Servin (2012). It was tested that whether differences in technical efficiency, both intra-firm and inter-firm, can be explained by differences in ownership, with a focus on non-governmental organisations, cooperatives and credit unions, non-bank financial intermediaries, and banks. The results showed that non-governmental organisations and cooperatives have much lower inter firm and intra firm technical efficiencies than non-bank financial intermediaries and banks, which indicates the importance of ownership type for technical efficiency.

Louis and Street (2013) applied self-organising map to investigate the association between social efficiency and financial performance using a comprehensive data set that included 650 MFIs. Result of the study supports the conclusion of Gutierrez-Nieto et al. (2009), Mersland and Strom (2010), and Quayes (2012). Significant, positive relationship between social and financial efficiency was found. 
However, results did not suggest a trade-off. Consequently, the theory that social performance comes at the prize of less financial performance did not seem to be valid.

\subsection{Studies focusing on sustainability of MFIs}

To provide micro-finance and other support services, MFIs should be able to sustain themselves for a long period. An enduring problem faced by any microfinance institution is how to attain financial sustainability. This section provides literature review of studies on sustainability of MFIs. Paxton (2002) and Nyamsogoro (2010) examined the trade-off between depth of outreach and sustainability of MFIs. The inverse relationship between depth of outreach and sustainability was found for other commonly used outreach proxies including average loan/GNP per economically active person, average annual loan/GNP, average annual loan size was found by Paxton. On the contrary, a positive relation between outreach and sustainability was found in another study conducted by Nyamsogoro. Rai et al. (2010) developed a model for measuring financial sustainability of MFIs by using five financial indicators such as portfolio at risk greater than 30 days, write off ratio, operating cost ratio, average number of active borrowers, operational self-sufficiency. The suggested model is useful for microfinance institutions to quantify the level of financial sustainability apart from checking whether they are financially sustainable or not.

Several studies have also been conducted, as well, to determine factors affecting the financial sustainability of MFIs using large and well developed MFIs in various countries. The level of significance of these factors in affecting the financial sustainability of MFIs, however, varies with studies. Some of the determinants are found to be significant in one economy or applicable to a set of MFIs, whereas some are found not to be significant. Studies conducted by Nyamsogoro (2010), Ayi and Sene (2010), Rai and Rai (2012), Kinde (2012), Kimando and Kihoro (2012) focused on determining factors affecting financial sustainability of MFIs in different countries. However methodologies applied by them were somewhat different. Ayayi \& Sene (2010) applied regression method and found that high quality credit portfolio, high interest rates, client outreach and age of MFI are major determinants of MFIs' sustainability, whereas Nyamsogoro (2010) used the accounting profitability theory approach to study the determinants of financial sustainability and found that outreach related factors such as microfinance capital structure, interest rates charged, differences in lending type, cost per borrower, product type, MFI size, number of borrowers and efficiency related factors yield on gross loan portfolio, level of portfolio at risk, liquidity level, staff productivity, operating efficiency are some factors that affect the financial sustainability of rural microfinance institutions in Tanzania. Rai and Rai (2012) applied regression method to 
identify the factors affecting financial sustainability of MFIs in India and Bangladesh only. Author also developed a financial sustainability index for the microfinance sector. They found number of active borrowers, percent of women borrowers, age, debt/equity ratio, capital/assets ratio, par $>30$ days, borrower per staff member, ROE and yield to be major determinants of financial sustainability of MFIs. Similarly Kinde (2012) identified factors affecting financial sustainability of MFIs in Ethiopia by applying panel data regression modelling by using least square method. He found that breadth of outreach, depth of outreach, dependency ratio and cost per borrower affect the financial sustainability of microfinance institutions in Ethiopia. Moreover, he also found that microfinance capital structure and staff productivity had insignificant impact on financial sustainability of MFIs in Ethiopia for the study periods. The conclusions made in the study implied that MFIs in Ethiopia should first minimize their dependency on donated capital to be operationally competent in the market, and then would become financially sustainable. Kimando and Kihoro (2012) used descriptive study to identify the factors and focused his study in Murang'a Municipality and also tried to identify whether financial regulations, geographical coverage and reach of the MFIs in Murang's municipality influence their sustainability. Results of the study exhibited that financial regulations, number of clients served, financial coverage and volume of credit transacted, geographical coverage were the factors that highly affected the sustainability of MFIs.

\subsection{Studies focusing on performance analysis of MFIs}

Now, focus of literature is shifting towards review of studies analysing the performance of MFIs. As it is believed that to look upon performance of MFIs is equally important when we are concerned about their efficiency and sustainability.

Shashua and Goldschmidt (1974) have attempted to develop a formal analytical model which constructs an index for evaluating the overall performance or success of a firm relative to any other firm in the same industry. Certain ratios such as profit margin, capital margin, returns to owners, equity ratio, working capital ratio, activity ratio, were considered indicators of success for the firms under analysis. The instrument developed in the study was found to be effective and efficient in determining the performance of a firm (or a group of firms) in relation to other firms (or groups) in a given year and over time. It would also serve as an indicator of economic progress and a useful tool for the management of the firm as well as for other agencies dealing directly with the firms (banks, government). 
Kereta (2007), Ejigu (2008), Llanto et al. (2008), Anduanbessa (2009) tried to give statistical insight in measuring the performance of MFIs in Ethiopia and also identified the determinants of their performance. Results of first study exhibited that deposit mobilised from clients, the number of active borrowers, and the gross loan portfolio load high on one component, average amount of loans disbursed to individuals, the financial revenue ratio and the cost per borrower ratio establishes the outreach performance dimension of the MFIs in the country. On the other hand, Ethiopian MFIs in general were found poor performers on depth of outreach in study conducted by Ejigu. They were not using their debt capacity properly, and they were found to be good at breath of outreach of management, efficiency and productivity. Kereta (2007), focused his attention on measuring performance of MFIs from different angles such as: i) look at the MFI outreach to the poor and their financial sustainability. ii) Challenges faced by MFIs iii) deliver policy recommendations towards efficient operation of MFIs. Results concluded that most of the MFIs were found operationally sustainable, measured by return on asset and return on equity. Another study in Indian context was conducted by Marakkath and Ramanan (2012) and they found that 12 MFIs appear efficient across both the models. Rest of the MFIs having efficiency scores of less than one, are regarded as less efficient. An interesting study was seen focusing on analysing the performance of independent MFIs in terms of cost efficiency, cash constraints and net portfolio in India providing microfinance services to low income clients (Vichor and Deshpande, 2012). This research facilitated other researchers to understand the role of microfinance in the Indian economy and to focus on the current performance of the sector in relation to financial services in the country in general. The study found that the high efficiency (low OER) of Indian MFIs played a key role in their profitability as did the significantly increased portfolio yield since 2007. Apart from financial performance of MFIs, Hien (2009) tried to highlight performance of Microfinance Institutions in Southeast Asia from regulatory perspective. He attempted to evaluate the impact of regulation on performance base to assess several core indicators of performance. The main finding of the study was that regulatory status had no effect on financial sustainability and outreach, which implies that the result of regulatory involvement of MFIs in Southeast Asia countries was similar with from cross-countries evidence. One more notable and interesting finding was MFIs in non-profit status or NGO have positively impact to outreach but negatively to financial sustainability and efficiency. Lafourcade et al. (2005) provided an overview of outreach and financial performance of MFIs in Africa. They basically, addressed two main questions in their study. Firstly, how does the performance of the African microfinance sector compare with that of its global peers? And secondly, how does performance vary among African MFIs? Results of the study 
indicated that overall financial performance of MFIs in Africa lags behind other global regions, a growing number of MFIs - especially regulated and cooperative MFIs - are profitable.

Luzzi and Webber (2006) illustrated how some statistical tools can offer new insights in the context of MFIs' performance evaluation. They attempted to shed some light on the way the performance of MFIs can be evaluated in a multi-dimensional context. Factor analysis, cluster analysis, seemingly unrelated regression (SUR) models were used for fulfilling the objectives. Findings of the study showed that the number of clients per loan officer had a positive and very significant impact on financial performance of MFIs. This variable probably indirectly captured labour productivity or efficiency in the MFI. The number of competitors was seemed to have a strong negative influence on the financial performance. Study concluded that a crucial aspect of financial sustainability could be the scrutiny of loan officers in granting credits. A study conducted by Assefa et al. (2010) focused on examining the relationship between competition and the performance of MFIs and also assessed the association between increased competition among MFIs. The focus of the analysis was on the relationship between competition and social and financial performance, controlling for macroeconomic, institutional and financial development variables. Findings revealed a general trend of increased competition in microfinance sector during the last decade. Result provided evidence that competition among MFIs is negatively associated with various measures of performance. The results with respect to social performance in terms of outreach showed that there is some evidence that higher competition is associated with lower outreach. All in all, then, the analysis supported the view of those who see increased competition and the related commercialisation of the microfinance sector as a potential threat to its longer term stability and success, especially in terms of its financial objectives.

Another study conducted by Singh (2012) tried to examine how source of funding impact the performance of MFIs and also compared financial and social performance of MFIs. Results exhibited some interesting findings: Firstly, average loan for shareholder funded MFIs was found to be higher compared to other MFIs. Secondly, Shareholder funded MFIs were found to have a lower return on assets compared to their counterparts. Thirdly, the yield on portfolio was equivalent for both categories of MFIs. Fourthly, in terms of operational self-sufficiency non shareholder funded MFIs marginally outperform their counterparts. Fifthly, cost per borrower and PAR for shareholder funded MFIs were higher compared to non-shareholder funded MFIs. In terms of breadth of outreach, shareholder funded MFIs performed far better than nonshareholder funded MFIs. 
Ashraf et al. (2014) analysed whether performance measures and their factors for MFIs in Muslim countries were significantly different from those in their non-Muslim counterparts, Results showed that country gross domestic product size was positively related with profitability, and the percentage of women borrowers was also significant in driving loan recovery and firm profitability in the OIC sample, but they were otherwise not significant for the rest of the world sample. Among the country-specific factors, country GDP size was found to have a significant impact on two measures of MFI outreach only in the sample of OIC countries. However, GDP size does not showed any significant impact on the loan loss ratio and loan loss provisions. Additionally, country GDP size has an overall negative impact on ROA, but a positive impact on the RYLD for the overall and OIC samples. Country GDP growth showed no impact on the MFI outreach measures in any sample.

\subsection{Summary and Conclusions}

Microfinance can undeniably be sustained in the long run in a profitable manner. The main solution is to endow it with multipurpose loans or composite credit for income generation. It is recommended for MFIs that the levels of efficiency have much more to do with proficient utilisation of resources rather than scale of production. A review of different studies exhibited the contradictory results while examining trade-off between outreach and sustainability. While few studies have shown that there exist an inverse relationship between depth of outreach and sustainability of MFI, there are other studies that exhibit a positive relation between both. So, it is difficult to be on one side. The main problem with MFIs is how MFIs deals with improving their operations in terms of increasing their outreach while at the same time reducing the costs of reaching out. Various researchers identified some major determinants of sustainability of MFIs such as: breadth of outreach, depth of outreach, dependency ratio, cost per borrower, geographical coverage, interest rates charged, age, capital structure, differences in lending type, product type, size, and efficiency related factors yield on gross loan portfolio, level of portfolio at risk, liquidity level, staff productivity. Studies focusing on performance analysis of MFIs suggest that MFIs in non-profit status or NGO have positive impact to outreach but negatively to financial sustainability and efficiency. Majority of studies reveal that the number of clients per loan officer had a positive and very significant impact on performance of MFIs. As the size of MFIs decreases in terms of gross loan portfolio, operational self-sufficiency and financial self-sufficiency decreases as well. In general, financial viability of the MFIs is found to be highly 
determined by the average amount of loans disbursed to individuals, the financial revenue ratio and the cost per borrower ratio.

Thus, it is suggested to MFIs that they should try to open several branches to reach as many people as possible and to make certain that they follow rules and regulations to survive well in the market. Also, in order to ensure effective regulation and supervision of the operations MFIs should be run by qualified members. So, it can be concluded from the findings that proper training is to be provided to the employees of MFIs especially in disbursing loans and collection of the loan amount to ensure efficiency and sustainability of MFIs.

\section{References}

Abayie, E.F., Amanor, K. \& Frimpong, J.M. (2011). The measurement and determinants of economic efficiency of microfinance institutions in Ghana: A stochastic frontier approach. African Review of Economics \& Finance, 2(2): 149-166.

Ahmad., Usman (2011). Efficiency analysis of microfinance institutions in Pakistan (Working Paper No. 34215). Retrieved from Pakistan Institute of Development Economics website: http://Mpra.Ub.UniMuenchen.De/34215.

Ali, Ashraf, Hassan, M.K. \& William J. H. (2014). Performance of Microfinance Institutions in Muslim countries, Humanomics, 30(2): 162-182.

(doi: http://dx.doi.org/10.1108/H-11-2013-0073).

Ayayi, A.G. \& Sene, M. (2010). What drives microfinance institution's financial sustainability. The Journal of Developing Areas, 44(1): 303-324.

Bayeh, A., \& Kinde, Snakew. (2012). Financial sustainability of MFIs in Ethiopia. (2012). European Journal of Business and Management , 4(15): 50-59.

Ejigu, Letenah. (2008). Performance analysis of a sample microfinance institutions of Ethiopia, Annals of Public \& Cooperative Economics, 79(2): 269-299.

Ferdousi, Farhana (2013). Performance of microfinance institutions in Asia: DEA based efficiency analysis, International Conference on The Modern Development Of Humanities \& Social Science, 91-94. doi:10.2991/mdhss-13.2013.23 
Nyamsogoro, G.D. (2010). Financial Sustainability of Rural Microfinance Institutions in Tanzania (Doctoral dissertation, University of Greenwich, London, England). Retrieved from http://gala.gre.ac.uk/6366.

Hassan, M. K., \& Sanchez, Benito (2008). Efficiency analysis of microfinance institutions in developing countries (Working Paper No. 453). Retrieved from Economic Research Forum at Network Financial Institute website: https://ideas.repec.org/f/pha425.

Hassan, M. K., Sanchez, Benito \& Ngene, G. (2012). Scales and technical efficiencies in Middle East \& North African (MENA) micro financial institutions, International Journal of Islamic \& Middle Eastern Finance \& Management, 5(2): 157-170.

Hermes, Niels, Lensink, Robert \& Meesters, Aljar. (2009). Outreach and efficiency of microfinance institutions, Centre For International Banking, Insurance \& Finance (CIBIF), Retrieved from http://ssrn.Com/Abstract=1396202.

Hermes, Niel, \& Lensink, Robert. (2011). Microfinance: Its impact, outreach, and sustainability. World Development, 39(6), 875-881.

Hien. V.M., (2009). Performance of Microfinance Institutions in Southeast Asia from Regulatory Perspective. Paper presented at Workshop on European Network on The Economics of The Firm, Paris, France. Retrieved from www.enef.group.shef.ac.uk/papers/Vu_Minh_Hien.pdf.

Kereta, B. B. (2007). Outreach and Financial Performance Analysis of Microfinance Institutions in Ethopia. African Economic Conference, United Nations Conference Center (UNCC), Addis Ababa, Ethiopia, 15-17. Retrieved from repository.uneca.org/unecawebsite/sites/.../files/.../befekadu_b_kereta.pd.

Kothakalla., R.R. (2013). Financial efficiency of Indian top five micro finance institutions. Global Journal of Interdisciplinary Social Sciences, 2(2): 6-15.

Mahanta, P., \& Gitanjali, P., S. (2012). Status of Microfinance in India - A Review, International Journal of Marketing Financial Services \& Management Research, 1(11): 142-155. 
Mamiza, Haq, M., Skully, M. \& Pathan, S. (2009). Efficiency of Microfinance Institutions: A Data Envelopment Analysis, Retrieved from http://Ssrn.Com/Abstract=1405709.

Marakkath, Nadiya, \& Ramanan, T., R. (2012). Assessing the efficient and sustainable performance of Indian MFIs. Cost Management, 26(5).

Nietoa, B.G., Cincaa, C.S., \& Molinero, C.M. (2007). Microfinance institutions and efficiency. International Journal of Management Sciences, 35: 131 - 142.

Nieto, B.G., Serrano, C.,C., \& Molinero, Mar. (2012). Social efficiency in MFIs. The Journal of The Operational Research Society, 60(1): 104-119.

Paxton, Julia (2002). Depth of Outreach \& Its Relation to the Sustainability of MFIs, Savings \& Development. 26(1): 69-86.

Louis, Philippe \& Street, A. (2013). Financial efficiency and social impact of MFIs using self-organising maps. World Development, 46: 197-210.

Pollinger, J. J., Outhwaite, John, \& Guzmanthe, H.C. (2007). Question of sustainability for microfinance institutions, Journal of Small Business Management. 45(1): 23-41.

Qayyum, Abdul, \& Ahmad, Munir (2010). Efficiency and sustainability of micro finance institutions in South Asia, 1-37, Pakistan Institute of Development Economics (PIDE) Report, Retrieved from https://ideas.repec.org/g/3193470.

Rai, A., K., \& Rai, S., K. (2012). Factors affecting financial sustainability of microfinance institutions. Journal of Economics \& Sustainable Development. 3(6): 1-9.

Rai, Anand, Kanwal, Anil \& Sharma, Meghna (2010). Financial sustainability of microfinance institutions: A New Model Approach. Asia-Pacific Business Review, 6(4): 12-17.

Rai, Anand (2012). A Comparative Analysis of the Financial Performance of MFIs of India \& Bangladesh, Noida, India, Jaypee Institute of Information Technology. 
Servin, R., Lensink, R., \& Marrit, V. D. B. (2012). Ownership and technical efficiency of microfinance institutions: Empirical evidence from Latin America, Journal of Banking \& Finance, 36: 2136-2144.

Shashua, L., \& Goldschmidt, Y. (1974). An index for evaluating financial performance. The Journal of Finance, 29(3): 797-814.

Singh, N.T. (2009). Micro finance practices in India: An overview. International Review of Business Research Papers, 5(5): 131-146.

Singh, Puran (2012). Funding structure and performance of MFIs in India: An empirical analysis of Indian MFIs, Gian Jyoti E-Journal, 1(3).

Tahir, I. Z., \& Tahrim, S. N. C. (2013). Efficiency analysis of microfinance institutions in ASEAN: A DEA approach, Business Management Dynamics, 3(4): 13-23.

Tariq, Masood \& Mohd. Izhar Ahmad. (2010). Technical efficiency of microfinance institutions in India- A stochastic frontier approach (MPRA Working Paper No. 25454). Retrieved from http://Mpra.Ub.Uni-Muenchen.De/25454.

Tsegaye, S. (2009). Statistical analysis of the performance of MFIs: The Ethiopian case. Savings \& Development, 33(2): 183-198.

Vichor, Sarita, \& Deshpande, Sangeeta (2012). Microfinance in India- A comprehensive analysis of the growth and performance of MFI. Research Journal of Social Science \& Management, 2(1): 51-56. 